\title{
PENGGUNAAN SOR SINGGIH BASA BALI PADA CERPEN BERBAHASA BALI SISWA SMP NEGERI 5 DENPASAR
}

\author{
Ni Putu Melda Andini ${ }^{1}$, I Ketut Riana ${ }^{2}$, Ni Made Dhanawaty ${ }^{3}$ \\ ${ }^{1,2,3}$ Fakultas IImu Budaya, Universitas Udayana \\ e-mail: melda.andini23@gmail.com¹, IKetutRiana12@gmail.com², \\ Dhanawaty07@gmail.com ${ }^{3}$
}

\begin{abstract}
Abstrak
Penelitian ini bertujuan untuk mengkaji penggunaan sor singgih basa Bali dalam cerpen berbahasa Bali siswa kelas VII SMP Negeri 5 Denpasar. Jenis penelitian ini adalah penelitian deskripsi kualitatif. Data penelitian ini adalah kalimat yang mengandung sor singgih basa Bali. Sumber data dalam penelitian ini adalah 28 cerpen karya siswa kelas VII SMP Negeri 5 Denpasar pada tahun 2019. Teknik pengumpulan data dilakukan dengan cara studi dokumentasi. Hasil penelitian ini, yaitu: (1) jenis kalimat sor singgih basa Bali berdasarkan tingkatannya yang digunakan pada cerpen berbahasa Bali siswa, meliputi alus singgih, alus sor, alus madya, alus mider, basa andap dan (2) penggunaan sor singgih basa Bali yang kurang tepat digunakan dalam cerpen berbahasa Bali siswa.
\end{abstract}

Kata kunci : Penggunaan Sor Singgih, Cerpen

\begin{abstract}
This research aimed at reviewing the use of sor singgih in Balinese Language short stories of the $7^{\text {th }}$ grade students of SMP Negeri 5 Denpasar. The type of this research was descriptive-qualitative research. The research data included the sentences that contained sor singgih basa Bali. The sources of data in this research were 28 short stories written by $7^{\text {th }}$ grade students of SMP Negeri 5 Denpasar in 2019. The data collection technique was conducted through documentation study. The results of this research were: (1) the type of consisted of alus singgih, alus sor, alus madya, alus mider, basa andap and (2) the improper uses of sor singgih basa Bali in short stories of the $7^{\text {th }}$ grade students.
\end{abstract}

Keywords : Use Sor Singgih, Short Stories

\section{PENDAHULUAN}

Bahasa Bali mempunyai dua dialek utama, dialek Bali Dataran (BD) dan dialek Bali Aga (BA) (Denes, 1982; Bawa, 1983; Clynes, 1995). Dialek BD umumnya digunakan di daerah dataran Pulau Bali termasuk daerah perkotaan seperti Denpasar dan jumlah penuturnya cukup banyak. Sebaliknya dialek BA kebanyakan digunakan di daerah pegunungan yang belum begitu berkembang dan jumlah penuturnya jauh lebih sedikit dibandingkan penutur dialek BD (Mayuko, 2015).

Sejak berabad-abad lalu, di Pulau Bali telah hidup berbagai etnik di samping etnik Bali. Kemajuan bidang ekonomi, khususnya terkait dengan bidang pariwisata menyebabkan Pulau Bali semakin dibanjiri oleh pendatang yang umumnya membawa serta budaya dan bahasa daerahnya masingmasing. Hal ini menjadikan Bali sebagai daerah yang multikultural dan sekaligus multilingual. Kendati di Bali hidup beberapa bahasa daerah, tetapi yang diangkat sebagai muatan lokal dalam kurikulum adalah bahasa Bali. Karena menjadi bagian dari kurikulum pendidikan, bahasa Bali, terutama di daerah perkotaan, juga dipelajari oleh para pembelajar yang multikultuaral dan multilingual. Dengan kata lain, bahasa Bali wajib dipelajari juga oleh siswa yang bukan penutur asli bahasa Bali (Dhanawaty, 2013).

Jika ada pertanyaan, apakah bahasa itu ? Kita sering mendapatkan jawaban yang beragam. Ada yang mengatakan bahasa adalah alat komunikasi. Mahasiswa jurusan 
bahasa yang sudah mulai mempelajari linguistik memberikan jawaban dengan mengemukakan defenisi bahasa secara teoritis dengan mengacu kepada buku-buku teks (linguistik) yang sampai ke tangan mereka. Pada tingkatan yang lebih kompleks, para peneliti dan mahasiswa jurusan bahasa telah sampai kepada rumusan konsep bahasa secara lebih mendalam dan terperinci. Mereka tidak hanya menyebut bahasa sebagai alat komunikasi tetapi analisisnya sudah mengalir sampai jauh. Bahasa memiliki peran yang sangat penting dalam kehidupan manusia (Oktavianus, 2013). Bahasa dapat membentuk realitas dan bahkan melebihi realitas yang disebut hiperrealiatas. Bahasa memiliki fungsi proteksi. Bahasa dapat digunakan sebagai alat pencitraan. Bahasa bahkan dapat mengubah situasi (Oktavianus, 2013).

Bahasa merupakan sebuah identitas. Melalui berbahasa kita dapat mengetahui asal seseorang. Bahasa Bali salah satu bahasa daerah di Indonesia sebagai bahasa ibu masyarakat Bali yang terancam punah. Bahasa Bali tidak lagi sebagai alat penghubung yang utama dalam berkomunikasi di keluarga, karena masyarakat khususnya diperkotaan lebih memilih bahasa Indonesia sebagai alat berkomunikasi. Keadaan ini sangat memprihatinkan bagi kita sebagai pemerhati bahasa Bali. Untuk mendukung bahasa bali sebagai identitas daerah, bahasa bali diwajibkan diajarkan di sekolah pada setiap jenjang. Karena akhir-akhir ini posisi bahasa Bali terancam oleh bahasa lain, misalnya di sekolah para siswa sering mengatakan bahwa bahasa Bali itu susah dan sayangnya terucap dari siswa yang memiliki latar belakang keluarga asli Bali. Melihat permasalahan seperti itu keluarga, sekolah dan masyarakat memiliki peranan penting di dalam dunia pendidikan.

Situasi kebahasaan pada komunitas tutur yang dwibahasawan atau multibahasawan menimbulkan kemungkinan pilihan baha- sa bagi masing-masing komunitas tutur. Sebagai konsekuensi pilihan bahasa terse- but adalah pola penggunaan bahasa. Pola penggunaan bahasa yang mantap menye- babkan adanya kebertahanan bahasa (lan- guage maintenance), sedangkan pola yang goyah menyebabkan pergeseran bahasa (language shift). Pembahasan tentang pe- mertahanan bahasa tidak bisa berdiri sen diri karena aspek ini berada dalam ruang lingkup kedwibahasaan, sikap bahasa, pergeseran bahasa, pilihan bahasa, dan perubahan bahasa. Salah satu isu yaitu me- ngenaisikap bahasa di bahas dalam tuli-san ini (Seri, 2013).

Salah satu cara untuk mengatasi hal tersebut adalah dengan meningkatkan kemampuan berbahasa Bali siswa terutama keterampilan menulis. Menulis merupakan salah satu kemampuan berbahasa yang sangat penting bagi siswa. Kemampuan menulis siswa harus terus ditingkatkan terutama kemampuan menulis cerpen. Pada siswa kelas VII SMP misalnya, diharapkan dapat menulis cerpen dengan benar. Dalam kemampuan menulis, kemampuan pengungkapan gagasan harus didukung oleh keterampilan bahasa yang digunakan (Depdiknas, 2003:5). Dalam menulis cerpen berbahasa Bali, siswa seharusnya memperhatikan penggunaan sor singgih basa Bali.

Bahasa Bali memiliki tingkatan-tingkatan bahasa sesuai dengan status dari lawan bicara. Tingkatantingkatan bahasa dalam Bahasa Bali disebut dengan Sor Singgih Basa Bali. Sor Singgih Basa Bali ini mengatur bagaimana seharusnya orang Bali berbicara kepada orang lain dengan status yang berbeda-beda, misalnya kepada orang yang dimuliakan (guru, pemuka agama), berbicara kepada orang yang belum dikenal, atau berbicara kepada orang tua dan teman. Adnyana menyebutkan beberapa alasan orang Bali mengalami kesulitan dalam mempelajari Sor Singgih Basa Bali. Pertama, mereka harus memilah dan memilih bahasa yang akan digunakan sesuai dengan siapa lawan bicara (siapa saja yang berbicara), berbicara tentang apa, dan kala apa berbicara. Kedua, kesulitan dalam membedakan Bahasa Bali Alus, yang mengakibatkan sulitnya menentukan dan memilih kata-kata Bahasa Bali yang sesuai sehingga dalam menyusun suatu kalimat sering terbalik antara Bahasa Bali Alus Sor dan Bahasa Bali Alus Singgih. Ketiga, faktor keluarga dan masyarakat yang lebih sering menggunakan bahasa Andap (bahasa biasa, bahasa pergaulan), bahkan bahasa kasar. Kemudian Wirawan [2] menyebutkan alasan lain sulitnya belajar Sor Singgih Basa Bali adalah keterbatasan pengetahuan tentang Bahasa Bali Alus, kurangnya sarana pembelajaran Bahasa Bali Alus yang menarik dan efektif, sulitnya menentukan kata yang masuk ke dalam Bahasa Bali Alus Singgih, Alus Sor, dan kosa kata yang dimiliki sangat kurang.( Bintari Ardita, 2015).

Menurut I Nengah Duija (2007:17), sor singgih basa Bali (tingkat-tingkatan bahasa Bali) yang digunakan sebagai alat komunikasi oleh masyarakat suku Bali mencerminkan 
pelapisan atau stratifikasi sosial masyarakat penutur bahasa tersebut, baik yang bersifat tradisional maupun yang bersifat modern dimana keduanya mempunyai pengaruh besar dan kuat terhadap sikap sopan santun dalam berkomunikasi. Penggunaan sor singgih bahasa Bali ini akan sekaligus mencerminkan identitas dan status sosial di antara mereka sebagai pembicara dan lawan bicara.

Berdasarkan uraian singkat di atas, peneliti bermaksud melakukan penelitian mengenai penggunaan sor singgih basa Bali yang terdapat dalam cerita pendek karya siswa kelas VII SMP Negeri 5 Denpasar. Tujuan dari penelitian ini adalah peneliti ingin mengetahui apa saja jenis sor singgih basa Bali yang digunakan pada cerpen berbahasa Bali siswa, meliputi alus singgih, alus sor, alus madya, alus mider, basa andap dan penggunaan sor singgih basa Bali yang kurang tepat dalam cerpen berbahasa Bali siswa. Hasil penelitian ini diharapkan dapat membantu meningkatkan hasil pembelajaran keterampilan menulis sehingga tidak terjadi lagi kesalahan yang sama dikemudian hari.

Dalam berbahasa Bali, setiap pembicara wajib memperhatikan, status dirinya, siapa mitra bicaranya, dan siapa yang dibicarakan. Kata-kata yang digunakan dalam kalimat pun akan bervariasi. Kalau membicarakan diri sendiri harus menggunakan kalimat-kalimat bahasa alus sor, kalau membicarakan sang singgih (orang terhormat) menggunakan kalimat alus singgih. Sementara, jika membicarakan keluarga sendiri harus menyebutnya dengan kata ganti ipun (dia) menggunakan kalimat alus sor (Suwija, 2014) Berikut merupakan penjelasan dari kalimat sor singgih basa Bali.

1. Kalimat alus singgih yaitu kalimat bahasa Bali yang bermakna halus, dipakai menghormati orang yang mempunyai status sosial lebih tinggi. Pada umumnya kalimat alus singgih dibentuk dengan kata-kata yang memiliki nilai rasa halus. Namun demikian, tidak semua kata-kata pembentuknya memiliki nilai rasa alus singgih.

2. Kalimat alus madia adalah kata bahasa Bali yang memiliki nilai rasa halus, namun terasa masih lebih rendahan sedikit akibat unsur pembentuknya masih ada dan cukup banyak kruna alus madia (kelompok kata menengah). Dengan demikian, kalimat alus madia ini akan dirasakan oleh penuturnya memiliki nilai rasa yang menengah.
3. Kalimat Alus Sor adalah kalimat bahasa Bali yang mengandung nilai rasa halus dan sering dipakai untuk merendahkan diri atau merendahkan orang lain karena status sosialnya lebih rendah.

4. Kalimat Alus Mider adalah kalimat yang digunakan berbicara bersamaan oleh orang yang berbicara dengan mitra berbicaranya. Kalimat alus mider kebanyakan dibentuk dengan katakata alus mider ditambah kata-kata mider

5. Kalimat Basa Andap adalah kalimat bahasa Bali yang mempunyai nilai rasa biasa, tidak kasar juga tidak halus. Kalimat bahasa andap digunakan dalam pembicaraan orang Bali antarsesama yang status sosialnya sama atau oleh orang yang berstatus sosial lebih tinggi terhadap yang lebih rendah

\section{METODE}

Penelitian ini termasuk jenis penelitian deskripsi kualitatif. Penelitian deskriptif kualitatif merupakan penelitian yang datanya berbentuk kata-kata atau gambar dan tidak menekankan pada angka (Moleong, 2006: 11). Sumber data penelitian ini adalah 28 cerpen berbahasa Bali siswa kelas VII SMP Negeri 5 Denpasar. Data dalam penelitian ini berupa kalimat-kalimat yang mengandung sor singgih basa Bali. Menurut Arikunto (2006: 129), sumber data adalah subjek dari mana data dapat diperoleh. Sumber data dalam penelitian ini adalah cerpen berbahasa Bali karya siswa kelas VII SMP Negeri 5 Denpasar. Instrumen penelitian adalah alat atau fasilitas yang digunakan oleh peneliti dalam mengumpulkan data agar lebih mudah dan hasilnya lebih baik, dalam arti lebih cermat, lengkap, dan sistematis, sehingga lebih mudah diolah (Arikunto, 2002: 123).

Instrumen penelitian yang digunakan adalah peneliti sendiri. Menurut Moleong (1988) dalam penelitian kualitatif, peneliti sendiri atau dengan bantuan orang lain merupakan alat pengumpulan data utama. Dalam hal ini peneliti terlibat dalam proses pembuatan instrumen soal dan proses pengumpulan data. Dalam prosesnya, kedudukan peneliti dalam penelitian kualitatif cukup rumit. Peneliti sekaligus merupakan perencana, pelaksana pengumpul data, menganalisis, penafsir data, dan pada akhirnya dia sebagai pelopor hasil penelitiannya. Pengumpulan data dalam 
penelitian dilakukan dengan cara studi dokumentasi.

Menurut Sugiyono (2009: 329), dokumen merupakan catatan peristiwa yang sudah berlalu. Penelitian ini menggunakan studi dokumentasi karena cerpen berbahasa Bali siswa kelas VII SMP Negeri 5 Denpasar termasuk dalam dokumen yang berbentuk tulisan. Dokumen bisa berbentuk tulisan, gambar, atau karya-karya monumental dari seseorang. Langkah-langkah pengumpulan data dalam penelitian ini adalah yang pertama peneliti mengumpulkan cerpen siswa kelas VII SMP Negeri 5 Denpasar, kedua peneliti membaca cerpen siswa kelas VII SMP Negeri 5 Denpasar dan terakhir peneliti melakukan analisis data. Teknik analisis data yang digunakan peneliti adalah teknik analisis kualitatif. Teknik ini digunakan untuk menganalisis penggunaan sor singgih basa Bali dalam cerpen berbahasa Bali siswa.

\section{HASIL DAN PEMBAHASAN}

Hasil analisis dari penelitian ini adalah Peneliti menemukan sebanyak 4 kalimat alus singgih, 14 kalimat alus sor, 10 kalimat alus madya, 11 kalimat alus mider, dan kalimat basa andap sebanyak 48 kata. Berikut merupakan contoh kalimat alus singgih yang terdapat dalam cerpen bahasa Bali siswa.

(1)"Bapak Kepala sekolah sampun usan ngicenin pawarah-warah"

Terjemahannya:

Bapak Kepala Sekolah sudah selesai memberikan nasehat.

Dari kalimat diatas menunjukkan bahwa kalimat tersebut termasuk dalam kalimat alus singgih. Hal tersebut dibuktikan dengan adanya kata "ngicenin". Dalam bahasa Bali, kata "ngicenin" biasanya ditujukan untuk orang-orang yang memiliki kedudukan dan status sosial lebih tinggi dari pembicara. Untuk itu kalimat tersebut termasuk dalam kalimat alus singgih.

(2) Ibu guru nunas mangda para sisiane meneng tur trepti.

Terjemahannya:

lbu guru meminta agar para siswa diam dan tenang.

Dari kalimat diatas menunjukkan bahwa kalimat tersebut termasuk kalimat alus singgih. Hal tersebut dibuktikan dengan kata meneng dan trepti. Dalam bahasa Bali, kata meneng dan trepti biasanya digunakan untuk orang yang memiliki status sosial lebih tinggi. Dari kalimat diatas terlihat bahwa siswa berbicara menggunakan bahasa alus singgih kepada gurunya (guru memiliki status sosial lebih tinggi dari siswa).

(3) Sesampune ngaturang pabaktian, para pamedek kaicenin wangsupada olih jero mangku.

Terjemahannya:

Setelah melakukan persembahyangan, para warga diberikan air suci oleh jero mangku (orang suci).

Dari kalimat diatas menunjukkan bahwa kalimat tersebut termasuk kalimat alus singgih. Hal tersebut dibuktikan dengan adanya kata "pamedek" dan "wangsupada". Kedua kata tersebut biasanya digunakan untuk orang yang lebih tinggi status sosialnya. Dalam kalimat tersebut ditunjukkan bahwa kedua kata digunakan untuk melakukan pembicaraan kepada orang suci (jero mangku).

Dalam cerpen berbahasa Bali siswa juga terdapat beberapa contoh kalimat alus mider. Berikut merupakan contoh kalimat alus mider.

(1) Ngiring iraga sareng sami jaga gumi Baline apang tetep trepti.

Terjemahannya:

Ayo kita bersama-sama menjaga Bali agar tetap tentram.

Dari kalimat diatas menunjukkan bahwa kalimat tersebut termasuk kalimat alus mider karena digunakan berbicara bersamaan oleh orang yang berbicara dengan mitra berbicaranya. Dalam bahasa Bali, ketika ada kalimat ajakan untuk mengajak seseorang melakukan sesuatu, itu termasuk kalimat alus mider. Dalam kalimat diatas, kata "ngiring" menunjukkan bahwa kata tersebut termasuk kalimat alus mider karena kata "ngiring" dalam bahasa Indonesia berarti ayo.

(2) Ni Nyoman Suiti ngajak timpalne ring kelas VIIG ngrastiti bakti mangda timpalne gelis kenak.

Terjemahannya:

Ni Nyoman Suiti mengajak temannya yang ada di kelas VIIG untuk mendoakan temannya yang sakit agar cepat sehat.

Dari kalimat diatas menunjukkan bahwa kalimat tersebut termasuk kalimat alus mider. Hal tersebut dibuktikan dengan kata "ngajak" yang berarti mengajak. Dalam kalimat tersebut terlihat bahwa $\mathrm{Ni}$ Nyoman Suiti mengajak temannya untuk berdoa bersama mendoakan temannya agar cepat sembuh dari sakitnya. Dalam bahasa Bali ditekankan ketika bertemu dengan kata ajakan, berarti kalimat tersebut termasuk kalimat alus mider. 
Beberapa contoh dari kalimat alus sor adalah sebagai berikut.

(1) Ipun mangkin jagi numbas jangan ka pasar.

Terjemahannya:

Sekarang dia akan pergi membeli sayur di pasar.

Dari kalimat diatas menunjukkan bahwa kalimat tersebut termasuk kalimat alus sor. Hal tersebut dibuktikan dengan kata "ipun" yang berarti dia. Dalam bahasa Bali, kalimat alus sor adalah kalimat bahasa Bali yang mengandung nilai rasa halus dan sering dipakai untuk merendahkan diri atau merendahkan orang lain karena status sosialnya lebih rendah. Kalimat diatas menggunakan kata "ipun" yang dimaksudkan untuk memberitahukan seseorang yang status sosialnya lebih rendah. Jika dalam bahasa Bali, untuk menghormati orang yang lebih tinggi status sosialnya biasanya menggunakan kata "ragane" yang berarti beliau. Namun dalam kalimat tersebut menggunakan kata "ipun" karena status orang yang dibicarakan adalah lebih rendah. Kalimat tersebut maksudnya adalah dia membeli sayur ke pasar.

(2) Meme titiange sampun ka pasar.

Terjemahannya:

Ibu saya sudah pergi ke pasar.

Dari kalimat diatas menunjukkan bahwa kalimat tersebut termasuk kalimat alus sor. Hal tersebut dibuktikan dengan adanya kata "titiange" yang berarti saya. Dalam bahasa Bali, kata "titiang" digunakan untuk merendahkan diri sendiri ke orang lain. Kalimat tersebut menunjukkan bahwa kata "titiang" sedang berbicara kepada orang yang lebih rendah status sosialnya.

Beberapa contoh dari kalimat alus madia adalah sebagai berikut.

(1) Tiang pacang melali ka Bedugul ajak timpal-timpale.

Terjemahannya:

Saya akan jalan-jalan ke Bedugul bersama teman-teman.

Dari kalimat diatas, menunjukkan bahwa kalimat tersebut termasuk kalimat alus madia. Hal tersebut dapat dibuktikan dengan adanya kata "pacang" yang artinya akan. Dalam bahasa Bali, kalimat alus madia adalah kalimat bahasa Bali yang memiliki nilai rasa halus, namun terasa masih lebih rendah sedikit akibat unsur pembentuknya masih ada.
Kata "pacang" tergolong kata bahasa Bali menengah karena jika diganti dengan kata lebih tinggi akan menjadi "jagi" dan jika diganti menjadi lebih rendah maka akan menjadi "lakar". Posisi kata "pacang" tersebut berada ditengah, maka kalimat tersebut termasuk kalimat alus madia. Kalimat diatas digunakan untuk berbicara kepada orang yang lebih rendah status sosialnya akan tetapi masih terlihat alus karena adanya kata "pacang". Untuk itu, kalimat diatas termasuk kalimat alus madia.

(2) "Ayu Sari saking dija?" keto patakon I Sarma.

Terjemahannya:

"Ayu Sari dari mana?" tanya I Sarma.

Dari kalimat diatas menunjukkan bahwa kalimat tersebut termasuk kalimat alus madia. Hal tersebut dapat dibuktikan dengan adanya kata "saking" yang artinya dari. Dalam bahasa Bali, kata "saking" tergolong ditengah karena jika diganti dengan kata yang lebih rendah maka akan menjadi kata "ull" dan jika diganti menjadi lebih tinggi maka akan tetap menjadi kata "saking". Kalimat tersebut menggunakan kata "saking" yang kedudukannya ditengah. Meskipun yang berbicara sedang melakukan pembicaraan dengan orang yang status sosialnya lebih rendah, kalimat tersebut tetap menjadi alus madia tidaklah alus singgih, karena adanya kata "saking" yang statusnya berada di tengahtengah.

Beberapa contoh dari kalimat basa andap adalah sebagai berikut.

(1) Mai alih malu timpale ke sekolah, Luh!

Terjemahannya:

Ayo cari dulu temanmu ke sekolah!

Dari kalimat diatas menunjukkan bahwa kalimat tersebut termasuk kalimat basa andap. Dalam bahasa Bali, basa andap adalah kalimat dalam bahasa Bali nilai rasa atau rasa basa-nya tidak alus dan tidak juga kasar. Dari kalimat diatas terdapat kata "mai" yang artinya ayo, "alih" yang artinya cari, "malu" yang artinya dulu, "timpale" yang artinya temenmu. Dalam bahasa Bali, semua kata tersebut tidak ada yang alus ataupun tidak ada yang kasar dan semua kata tersebut digunakan untuk berbicara kepada orang yang status sosialnya rendah sehingga kalimat diatas termasuk kalimat basa andap.

(2) Nah yen suba keto, mai majalan ka Bedugul!

Terjemahannya:

Baik jika sudah seperti itu, mari jalan ke Bedugul!

Jurnal IImu Sosial dan Humaniora| 109 
Dari kalimat diatas menunjukkan bahwa kalimat tersebut termasuk kalimat basa andap. Hal tersebut dapat dibuktikan dengan adanya beberapa kata yang disusun yaitu kata "nah" yang artinya baiklah, "yen" yang artinya jika, "suba" yang artinya sudah, "keto" yang artinya seperti itu, "mal" yang artinya mari, "majalan" yang artinya jalan, termasuk kata yang tidak alus dan tidak kasar. Dalam bahasa Bali, kalimat basa andap juga menunjukkan bahwa yang berbicara sudah memiliki keakraban dengan orang yang diajak berbicara sehingga bahasa yang digunakan tidak alus dan juga tidak kasar. Kalimat tersebut juga menunjukkan bahwa yang berbicara sudah akrab dengan yang diajak berbicara, untuk itulah kalimat tersebut termasuk kalimat basa andap.

Dalam cerpen berbahasa Bali karya siswa kelas VII SMP Negeri 5 Denpasar juga terdapat beberapa kesalahan dalam penulisan sor singgih basanya. Berikut adalah beberapa contoh kesalahan penggunaan kalimat sor singgih basa yang terdapat dalam cerpen berbahasa Bali siswa.

(1) Kalimat alus singgih.

"Ibu guru ngicenin pawarah-warah di kelase"

Terjemahannya:

Ibu guru memberikan pengarahan di kelas.

Dari kalimat diatas, menunjukkan kalimat alus singgih akan tetapi terdapat kesalahan pada kata "d". Dalam bahasa Bali, kalimat alus singgih adalah kalimat yang memiliki nilai rasa atau rasa basa yang sangat hormat, dan digunakan untuk menyatakan seseorang atau sesuatu yang patut dihormati. Dalam kalimat diatas, terdapat kalimat yang menunjukkan pembicaraan kepada orang yang statusnya lebih tinggi dan harus dihormati yaitu ibu guru. Kata "ngicenin" menunjukkan kata alus singgih, akan tetapi kata "di" seharusnya diganti dengan kata "ring" agar pengucapannya benar mengingat kalimat tersebut ditujukan kepada orang yang statusnya lebih tinggi dan harus dihomati.

(2) Kalimat alus sor.

\section{"Timpal titiange nenten nawang."}

Terjemahannya:

Teman saya tidak tau.

Dalam kalimat diatas menunjukkan bahwa kalimat tersebut termasuk kalimat alus sor. Dalam bahasa Bali, kalimat alus sor adalah kalimat untuk merendahkan diri sendiri ke orang lain. Kalimat tersebut menunjukkan bahwa kata "titiang" sedang berbicara kepada orang yang lebih rendah status sosialnya. Akan tetapi, terdapat kesalahan dalam kalimat tersebut sehingga terkesan sedikit kasar. Kata yang dimaksud adalah kata "nawang". Kata "nawang" seharusnya diganti dengan kata "uning" agar lebih alus. Jika menggunakan kata "nawang" maka kalimat tersebut terlihat lebih kasar dibandingkan dengan kata "uning".

(3) Kalimat alus madia.

"Nggih Luh, jani tiang merika."

Terjemahannya:

Baik Luh, sekarang saya kesana. Dalam kalimat diatas, menunjukkan kalimat alus madia. Hal tersebut dapat dibuktikan dengan kata "nggih" yang artinya baik. Akan tetapi terdapat kesalahan dalam kalimat tersebut yaitu kata "jani". Kalimat alus madia adalah kalimat yang memiliki nilai rasa atau rasa basa menengah, namun tetap alus atau hormat. Pada kalimat diatas, termasuk kalimat alus madia karena semua kata-kata yang disusun termasuk golongan ditengah akan tetapi terdapat kesalahan pada kata "jani". Seharusnya kata "jani" diganti dengan kata "mangkin" agar kalimat tersebut tetap terlihat alus dan menengah.

(4) Kalimat alus mider.

"Mai je iraga sareng-sareng malajah ! keto ibu guru ngajakin."

Terjemahannya:

Mari kita bersama-sama belajar ! begitu ibu guru berkata.

Dalam kalimat tersebut, terdapat kesalahan dalam penulisan kata yaitu kata "mai". Kata "mai" seharusnya diganti dengan kata "ngiring" agar terkesan lebih alus karena kalimat alus mider bertujuan untuk mengajak seseorang melakukan sesuatu dengan menggunakan kalimat yang alus.

(5) Kalimat basa andap.

"Luh, sing dadi keto ajak timpal, ajak timpale sareng-sareng malajah." 
Terjemahannya:

Luh, tidak boleh seperti itu dengan teman, ajak temanmu belajar bersama.

Dari kalimat diatas menunjukkan bahwa kalimat tersebut termasuk kalimat basa andap. Hal tersebut dibuktikan dengan setiap katanya disusun dengan menggunakan kata andap. Basa andap biasanya digunakan berbicara dengan orang yang sudah dikenal dan status sosialnya lebih rendah. Akan tetapi, terdapat kesalahan dalam kata yang disusun yaitu kata "sareng-sareng". Kata "sareng-sareng" seharusnya diganti dengan menggunakan kata "barengbareng" agar terkesan tidak terlalu alus.

\section{PENUTUP}

Hasil Dari hasil analisis penelitian ini dapat disimpulkan bahwa terdapat 5 jenis kalimat sor snggih basa yang terdapat dalam cerpen berbahasa Bali siswa kelas VII SMP Negeri 5 Denpasar yaitu kalimat alus singgih, kalimat alus sor, kalimat alus madia, kalimat alus mider dan kalimat basa andap. Peneliti menemukan sebanyak 4 kalimat alus singgih, 14 kalimat alus sor, 10 kalimat alus madya, 11 kalimat alus mider, dan kalimat basa andap sebanyak 48 kata.

Dalam cerpen berbahasa Bali siswa kelas VII SMP Negeri 5 Denpasar juga terdapat beberapa kesalahan dalam membuat kalimatnya yaitu kalimat alus singgih terdapat 1 kesalahan, kalimat alus madia terdapat 3 kesalahan, kalimat alus mider terdapat 3 kesalahan, kalimat alus sor terdapat 2 kesalahan dan kalimat basa andap terdapat 5 kesalahan.

\section{DAFTAR PUSTAKA}

Bintari, Ni Kadek Ardita. 2015. Aplikasi Pembelajaran Bahasa Bali Alus Dengan Phonegap (Melajah Basa Bali) .Jurnal e-Proceeding of Applied Science : Vol.1,
No.3 Desember 2015 Prodi D3 Manajemen Informatika, Fakultas IImu Terapan, Universitas Telkom

Arikunto, S. 2006. Prosedur Penelitian Suatu Pendekatan Praktik. Jakarta: Rineka Cipta.

Dhanawaty, Ni Made. 2013. Perlunya Pembelajaran Bahasa Bali Yang Rekreatif Di Sekolah Dasar Multikultural Dan Multilingual . Jurnal Madah, Volume 4, Nomor 2, Edisi Oktober 2013 Fakultas Sastra Universitas Udayana, Jalan Nias 13 Denpasar, Bali

Depdiknas. 2003. Pendekatan Kontekstual, tentang Contextual Teaching and Learning. Jakarta: Depdiknas.

Mayuko, Hara. 2015. Bentuk Hormat" Dialek Bahasa Bali Aga Dalam Konteks Agama . Jurnal Linguistik Indonesia, Volume ke33, No. 2, Agustus 2015 Osaka University

Moleong, Lexy J. 2006. Metodologi Penelitian Kualitatif. Bandung: Remadja Karya CV.

Oktavianus. 2013. Bahasa Yang Membentuk Jati Diri Dan Karakter Bangsa . Journal Arbitrer, Vol. 1 No. 1 Oktober 2013

Seri, Ni Luh Nyoman Malini. 2013. Sikap Generasi Muda Terhadap Bahasa Bali Di Destinasi Wisata Internasional Bali. Jurnal Bahasa Dan Seni, Tahun 41, Nomor 2, Agustus 2013 Universitas Udayana

Sugiyono. 2009. Metode Penelitian. Bandung: Alfabeta.

Suwija, I Nyoman. 2014. Tata Titi Mabaos Bali. Denpasar: Pelawa Sari. 